\title{
The words used to sell psychotropic drugs
}

\author{
Matthew Jelley, Senior Registrar in Psychiatry, Fromeside Clinic, Stapleton, Bristol \\ BS16 1ED and JoHN H. OwEN, Lecturer in Mental Health, University Department of \\ Mental Health, 41 St Michael's Hill, Bristol BS2 8DZ
}

\begin{abstract}
Advertisements are biased. This is not a statement of ideology, but a statement of fact. They are neither public service announcements nor balanced debates. They exist solely to encourage the consumer to buy one product in preference to another. The importance of this is that, as clinicians, we often place ourselves apart from others when considering what influences our practice. On the one hand our training emphasises a combined approach of pharmacological, psychological, and social therapies, but on the other, it is only the pharmacological approach that has the ability to finance full-colour advertisements in learned journals. In 1982 the pharmaceutical industry spent $\mathrm{f} 150$ million on drug promotion in the UK (Medawar, 1984). We have attempted to take an objective view of drug advertisements by examining the words used in all advertisements that have appeared in the British Journal of Psychiatry over the last 30 years.
\end{abstract}

\section{Panaceas?}

Over the years pharmaceutical companies have often subtly implied that medication is a panacea for problems well beyond formal psychiatric illness. One current example is an advertisement for Prothiaden (dothiepin 1991) which simply has the caption "I just can't cope". The implication, therefore, is that the correct response to a patient saying they cannot cope is to prescribe an antidepressant. Confusingly, when this has occurred before ("I feel I just can't cope any more" Benvil [tybamate] 1969) the correct response was to prescribe an anxiolytic! Other advertisements have included vague indications such as "emotional disturbance" (Motival [nortriptyline and fluphenazine] 1974) or "any manifestation of emotional distress (Prothiaden 1971).

When distress is caused by environmental factors, advertisements can still exert a pressure to prescribe rather than address the underlying stressors. A young mother on a new housing development ponders, "why did we ever come here?" suggesting a prescription for Amylozine (trifluoperazine and amylobarbitone 1962) and in another advertisement a set of pictures portray that whether "stress is ... occupational, financial, physical, marital, environmental or antisocial", the answer is Fluanxol (flupenthixol 1977). Similarly one is actively distracted from looking at what might be causing anxiety or depression by such advertisements as "Anxiety whatever's behind it - Ativan" (lorazepam 1977).

As a rule, neuroleptics escape over-broad indications with a notable exception being an advertisement for Neulactil (pericyazine 1970)-"when people suffer from people Neulactil pulls people together". It goes on to suggest using the product not only as a "behaviour corrective" for "antisocial or abnormal behaviour in the juvenile adolescent or elderly" but also as an anxiolytic for the "tension states" that the behaviour produces within the "family or social group"!

In an advertisement for nortriptyline it is the doctor who is being treated as well as the patient "when you prescribe Aventyl you take a load off two minds" (1961), an indication we were unable to find in the BNF

\section{Educational?}

An argument often advanced in favour of drug advertising is that it is educational - it serves to make the doctor more aware of available drugs and their uses. Most of the information, however, is very basic and would seem to be aimed primarily at GPs or general hospital doctors. "Education" aimed at the psychiatrist has been surprisingly thin on the ground, with opportunities being ignored. One might, for example, take two reasonably important advances of recent years. Lithium has been licensed for the control of aggressive behaviour since 1988-no advertisements have promoted this aspect of the drug. Similarly, Carbamazepine has been licensed for the prophylaxis of manic depressive illness since 1988 - no advertisements have appeared for this. The absence of a clear specialist educative element would support the notion that the main purpose of advertisements in the journal is to maintain brand loyalty.

\section{Informative?}

The specific indications for particular drugs as conveyed in advertisements can at time be confusing. For instance, in the early ' 60 s a group of advertisements established Stelazine (trifluoperazine 1964) as 
"the tranquilliser with the unique alerting action" and the pictures are of withdrawn, catatonic patients. On the other hand, a group of advertisements showing a "violently agitated and hostile schizophrenic" was run with the caption "Stelazine quickly calms" (1965). In a similar vein Clopixol (zuclopenthixol) was initially marketed for "the agitated, aggressive, overactive schizophrenic" (1978), but in 1984, it became "the broad spectrum antipsychotic" and reference to aggression etc. was dropped from its advertisements. Surprisingly then its data sheet still lists its indications as "psychosis ... particularly ... with features of agitation or aggression" (1990).

The elderly generally do not fare well in their portrayal. A series of advertisements for Sparine (promazine 1975) describes "the face of unrest" and explains how "Sparine allows senile patients to grow old without growing troublesome". This aspect of the "nuisance value" of the elderly is highlighted in other advertisements such as ones depicting an elderly person throwing his food across the table (Neulactil [pericyazine] 1968) or "granny becoming vulgar" (Praxilene [naftidrofuryl] 1974).

It is salutary to note that concern about the cost of treatment is not new. As early as 1962 Largactil (chlorpromazine) was promoted as "the product that pays for itself". In the same year we were told Fentazin (perphenazine) "compresses mental health prescription costs". Apparently a week's treatment cost 1 shilling and 5 pence $(7 \mathrm{p})$.

It is useful to conclude by mentioning products that have failed to live up to their promise, e.g. in 1961 Librium (chlordiazepoxide) was hailed as "the successor to the tranquillisers"! In 1982 advertisements for zimeldine claimed "Zelmid ... gives you the efficacy you need without the problems you don't". In 1983 it was withdrawn following reports of associated Guillain Barre Syndrome. In 1986 Merital (nomifensine) was withdrawn because of the risk of haemolytic anaemis with intravenous haemolysis; it had been marketed from 1978 onwards under the slogan "Hit the depression, not the patient".

\section{Acknowledgements}

The advertisement shown is reproduced with the kind permission of Allen \& Hanburys Ltd, and does

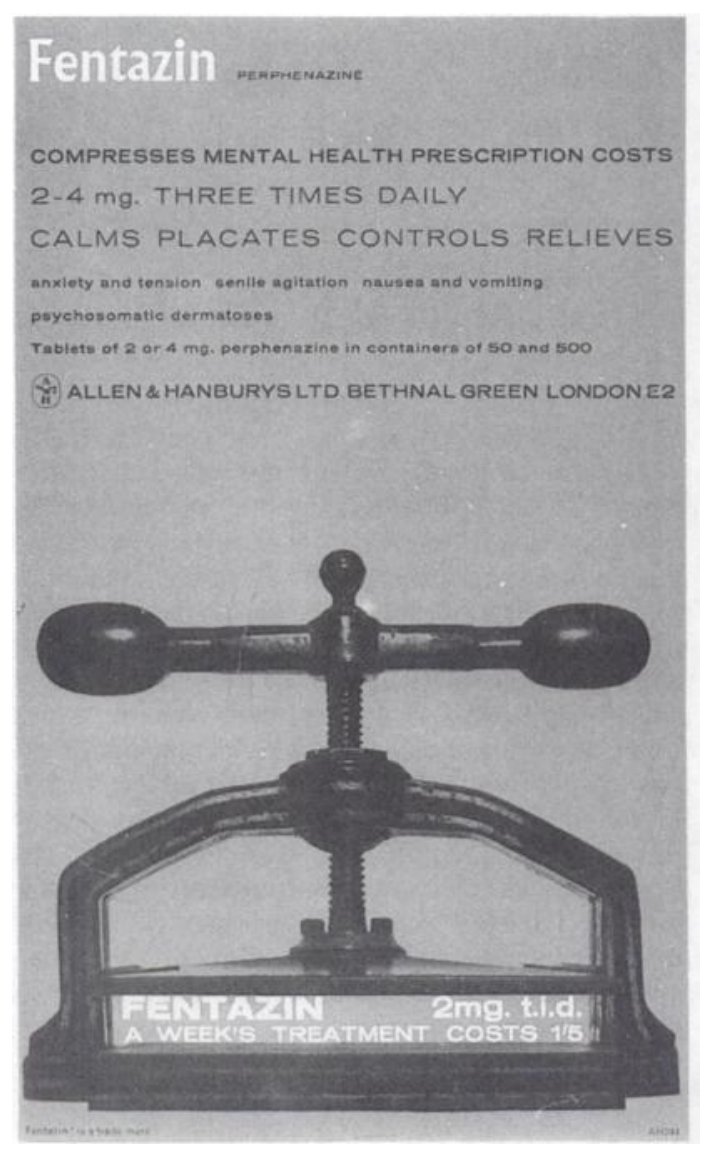

not necessarily conform to the current ABPI Code of Practice.

\section{Reference}

Medawar, C. (1984) The Wrong Kind of Medicine. London: Consumers' Association and Hodder \& Stoughton.

\section{Note}

'Images to sell psychotropic drugs' will appear in the January 1992 issue of the Psychiatric Bulletin. 